\title{
LAS INVENCIONES LABORALES EN EL DERECHO ESPAÑOL Y CHILENO
}

\author{
Alfredo Sierra Herrero*
}

RESUMEN: Este trabajo discurre acerca del estatuto jurídico de las invenciones de los trabajadores contratados para ello, comúnmente denominadas invenciones laborales. Revisa la legislación española a este respecto en su calificación y distinción en el ámbito objetivo en invenciones patentables, modelos de utilidad, adiciones y otros tipos de protección exclusiva; y en el ámbito subjetivo, describe la vinculación con las relaciones laborales, de servicios, de alto directivo $y$ de funcionarios públicos. Se revisan las invenciones producidas por profesores de universidad y personal investigador de entes públicos de investigación. Se expone una clasificación, se tratan los deberes y derechos en el régimen de invenciones laborales, así como en particular las invenciones laborales en ámbito de los diseños industriales. Finalmente se pasa revista a las invenciones laborales en Cbile, repitiendo el mismo esquema anterior.

Palabras clave: Invenciones laborales - Invenciones patentables Modelos de utilidad - Adiciones - Personal investigador - Diseños industriales.

ABSTRACT: This work deals with the legal framework of employee's inventions, ordinarily named labour inventions. It reviews the several ways in which Spanish law protects patentable inventions, utility models and other titles of industrial property rights. From a perspective of working relationship, the article describes the linkage between labour inventions and some types of qualified employees, like bigh level executives or public officials. It also examines the inventions produced by university professors or by other researchers working at public institutions. A classification is exposed. Rights and obligations in the labour inventions regime are presented, in particular within the Industrial Design area. Finally, attention is devoted to labour inventions under chilean Law.

Abogado y Licenciado en Derecho, Universidad de Chile. Ha sido abogado de la Cámara Chilena de la Construcción, miembro de la Comisión Laboral de la Confederación de la Producción y del Comercio. Miembro del estudio Allende Bascuñán y Cía., en Santiago (Chile). Correo electrónico: asierra@abcia.cl Artículo recibido el 17 de septiembre de 2004. Aceptado por el Comité Editorial el 6 de diciembre de 2004. 
Key words: Labour inventions - Patentable inventions - Utility models - Additions - Research staff - Industrial Designs.

SUMARIO: I. Introducción. II. Evolución de la normativa en España. III. Regulación de las invenciones laborales en España. IV. Clasificación de invenciones laborales. $V$. Deberes y derechos en el régimen de invenciones laborales. VI. Invenciones laborales en los Diseños Industriales. VII. Regulación de las invenciones laborales en Chile. VIII. Conclusiones. Abreviaturas y bibliografía.

\section{INTRODUCCIÓN}

Actualmente la mayor parte de la investigación se desenvuelve en el seno de empresas, universidades o centros públicos de investigación. Lo anterior, debido a que la búsqueda de invenciones relevantes precisan, considerando el grado de organización y complejidad del estado mundial de la técníca, de cuantiosas inversiones en recursos materiales y humanos, que solo pueden asumir organizaciones de cierta entidad estructural y financiera. Esta situación ha propiciado un cambio en la organización del trabajo creativo que hoy se lleva a cabo normalmente en equipo y por inventores asalariados. De esta forma, cada vez son menos frecuentes las invenciones producto del trabajo solitario de una persona, que dotada de escasos medios y enormes dosis de intuición y paciencia logra desarrollar una idea luminosa aplicable a la técnica ${ }^{1}$.

Al hecho de que el inventor independiente no dispone de medios, debe añadirse que, en la mayoría de los sectores de la industria, especialmente la químico farmacéutica, microelectrónica, informática, etc. se necesitan verdaderos equipos investigadores que trabajen de manera continua y sistemática. De manera que en tales ámbitos resulta casi imposible obtener logros producto del trabajo de una sola persona ${ }^{2}$.

Teniendo en cuenta esta realidad, referida a que solo empresas e instituciones son capaces de emprender estos desafíos, se comprende que tales entidades sean los titulares de las invenciones alcanzadas por trabajadores contratados para ello, las que se denominan comúnmente como invenciones laborales.

Dada la relevancia de esta materia, muchos países, incluidos España y Chile, han modernizado en este último tiempo sus legislaciones con el objeto de actualizar su regulación. Ahora bien, esta es una cuestión que presenta dificultades de armonización entre los distintos ordenamientos,

Lema Devesa, Carlos: "Las invenciones laborales en la Ley de Patentes de 20 de marzo de 1986", en Derecho y Tecnología, curso sobre innovación y transferencia (dir. y coord. por J. Bisbal/C. Viladás), Ariel, Barcelona, 1990, p. 146. 
por lo que generalmente no ha sido un tema abordado en Convenios internacionales ${ }^{3}$. En efecto, el Convenio de Munich sobre la Patente Europea, de 5 de octubre de 1973 , renuncia a establecer una regulación uniforme del derecho a la patente europea en los supuestos de invenciones laborales y encarga el problema a las legislaciones nacionales. El mismo camino adopta el Convenio sobre Patentes Comunitarias ${ }^{4}$, que se remite sobre este punto al convenio antes citado. Por tal motivo, los llamados a afrontar este asunto son los ordenamientos nacionales, que a lo menos deben determinar a quién corresponde el derecho de patente. Precisamente del estudio de la regulación española sobre el tema expuesto tratarán los siguientes apartados, partiendo de una revisión de la evolución experimentada por esta legislación, y siguiendo con un análisis sobre las disposiciones actualmente vigentes. Finalmente, nos referiremos a la regulación existente en Chile.

\section{EVOLUCIÓN DE LA NORMATIVA EN ESPAÑA}

Tradicionalmente España se había caracterizado por regular estas invenciones por normas del Derecho Laboral. Ellas se contemplaron, por primera vez, en los artículos 24 y 25 de la Ley de Contrato de Trabajo de 21 de noviembre 1931, no teniéndose en cuenta en el Estatuto de Propiedad Industrial de 26 de julio 1929. Posteriormente, la citada ley fue derogada por la LCT de 27 enero 1944, pero el régimen de invenciones laborales no sufre alteración, ya que lo dispuesto sobre este punto en la Ley de 1931, es reproducido literalmente en los artículos 29 y 30 en la nueva ley. En tales disposiciones, se distinguían tres clases de invenciones laborales. En primer lugar, las invenciones de empresa o de taller, referidas a aquellas en que predominaba el proceso, las instalaciones, métodos y procedimientos de la empresa sin distinción de persona alguna que lo obtuviese. Estas invenciones pertenecían al empresario, para lo cual debían prevalecer en estas los elementos antes mencionados.

En segundo lugar, se encontraban las invenciones de encargo, consistentes en innovaciones realizadas por trabajadores contratados para estudiarlas y obtenerlas, cuya titularidad la ley otorgaba al empresario. Por último, se contemplaban las invenciones libres, caracterizadas por la preponderancia de la personalidad del trabajador en su logro. Esta clase de invención pertenecían al trabajador, considerándose nula su renuncia previa a la propiedad de la invención. Esta categoría fue objeto de fuertes

Vid. Blanco Jiménez, Araceli: Protección Jurídica de las Invenciones Universitarias y Laborales, Aranzadi, Navarra, 1999 , p. 63.

4 El mencionado Convenio fue firmado el 15 de diciembre de 1975 y modificado el 15 de diciembre de 1989. 
críticas por estimarse que lesionaba gravemente los intereses del empresarios.

Luego, la Ley de 1944 fue reemplazada por el Estatuto de los Trabajadores de 1980, el cual, por mandato de su disposición adicional final cuarta, mantuvo en vigor los artículos 29 y 30, de la ley derogada, en carácter de normas reglamentarias. Es decir, sustantivamente dicho Estatuto no presentaba novedades con respecto al tema en análisis.

Este escenario de reglamentación, a través de normas ajenas a la propiedad industrial, se mantuvo hasta la entrada en vigor de la Ley 11/ 1986, de 20 marzo, de Patentes, que derogó expresamente las disposiciones indicadas (apartado 3 de la disposición derogatoria de la LP). Esta Ley tiene sus antecedentes en varios Anteproyectos y Proyectos en los que, por primera vez, dentro del marco de la legislación de patentes en España se consideraban las invenciones laborales. El motivo de este cambio de ubicación era quizás el resultado de la estimación que esta materia desborda el ámbito de una legislación laboral, entendiéndose más propia de una legislación de patentes, por tratarse en el fondo de un tema de propiedad industrial ${ }^{6}$. Sobre el particular, en el preámbulo de la citada ley se señala que la inclusión de la reglamentación de las invenciones laborales dentro de una ley de patentes responde a la realidad actual del propio proceso productivo, que ha sido el criterio seguido por la generalidad de las leyes de patentes europeas.

Como puede apreciarse, la entrada en vigencia de la Ley 11/1986 provocó un cambio relevante en el tratamiento legal de las invenciones laborales, consistente en el abandono de su regulación por leyes laborales, adoptándose, como contrapartida su ordenación por leyes de Propiedad Industrial.

\section{REGULACIÓN DE LAS INVENCIONES LABORALES EN ESPAÑA}

Las invenciones laborales se encuentran reguladas dentro de la LP, en su Título IV (que precisamente recibe dicha denominación) que trata el régimen jurídico aplicable y en el Capítulo IV del Título XII, que se refiere a la conciliación en este tipo de materias. La disposición básica

Vid. Lema Devesa, Carlos: (n. 1), p. 147.

ESTUPIÑÁN CÁCERES, Rosalía: Las invenciones laborales en la empresa, Editoriales de Derecho Reunidas, Madrid, 2003, pp. 57 y 73, da cuenta de esta hipótesis criticándola, indicando que la problemática de las invenciones laborales no solo excede el ámbito de una Ley Laboral, sino también de una Ley de Patentes, si se quiere tomar en consideración, de una forma global todo el fenómeno y problemática de esta clase de invenciones. En su concepto lo más acertado sería la regulación de las invenciones laborales en una ley específica, principalmente porque de esta forma no se restringe innecesariamente su ámbito objetivo y subjetivo de aplicación. 
que conceptúa esta figura es el artículo 15.1 LP, el cual dispone que: "las invenciones, realizadas por el trabajador durante la vigencia de su contrato o relación de trabajo o de servicios con la empresa, que sean fruto de una actividad de investigación explícita o implícitamente constitutiva del objeto de su contrato, pertenecen al empresario". Esta norma debe ser complementada por el artículo 17.1 LP que también incluye dentro de esta clase de invenciones a aquellas que el trabajador obtenga influido predominantemente por los "conocimientos adquiridos dentro de la empresa o la utilización de medios proporcionados por esta", en cuyo caso "el empresario tendrá derecho a asumir la titularidad de la invención o reservarse un derecho de utilización de la misma".

De tales preceptos, es posible colegir los ámbitos de aplicación de esta normativa: El ámbito objetivo comprende creaciones realizadas por asalariados que consistan en invenciones, cuya titularidad pertenecerá a la empresa. Por su parte, el ámbito subjetivo son aquellos sujetos vinculados a la empresa donde llevan a cabo su actividad profesional.

A continuación analizaremos con mayor detención cada uno de ellos.

\section{A. Ámbito objetivo}

La delimitación de esta esfera implica indagar sobre la expresión invención. La LP no formula una definición positiva, sino que se limita a indicar una serie de actividades que no se consideran invenciones, y además enumera los requisitos que debe reunir la invención. Ahora bien, la mayoría de la doctrina ha señalado que se trata de una "regla técnica para solucionar un problema técnico" ${ }^{7}$, de este modo se deduce que siempre debe haber un problema técnico, enlazado causalmente con una solución, que también tendrá que ser técnica ${ }^{8}$.

Sobre este punto, debe precisarse si el régimen jurídico en análisis es aplicable solo a las invenciones patentables o también se comprenden las no patentables. Parte de la doctrina ${ }^{9}$, basándose en el artículo 19.1 LP, a cuyo tenor: "las invenciones para las que se presente una solicitud de patente o de otro título de protección exclusiva (...)", señala que solo pueden conceptuarse como tales, las invenciones protegibles por patentes, incluidas las adiciones (artículos 108-111) y los modelos de utilidad (artículos 143-154), ya que se trata de los únicos títulos de protección exclusiva reglamentados por la LP. En cambio, otros autores ${ }^{10}$, también fundándose en el artículo precedente (especialmente los términos; otro título de protec-

Para un estudio más detallado del concepto de invención consultar GOMEZ SEGADE, José Antonio: "Patentabilidad", en Fernández NovoA, C. y GOMmZ Segade, J. A.: La modernización del Derecho Español de Patentes, Montecorvo, Madrid, 1984, p. 50.

Ibid.

BlanCO Jiménez, Araceli: (n. 3), p. 119.

Ibid. p. 80. 
ción exclusiva), advierten que esta normativa abarca tanto las invenciones que son patentables (incluidos las adiciones y modelos) como las que sin serlo, pueden ser protegibles por otras modalidades de Propiedad Industrial. Además, se indica que esta interpretación evita que para los contratantes surjan incertidumbres acerca de sus derechos y obligaciones, desde el momento en que la calificación de un invento como patentable o resguardada por otro título de protección exclusiva es una cuestión objetiva que no depende de la voluntad de ellos, sino de los requisitos legales del Derecho Industrial, resultado muchas veces difícil para ellos saber si la invención reúne o no esos requisitos.

Parece ser más acertado este último criterio, ya que examinando el mencionado artículo 19.1, este se refiere a "otros título de protección exclusiva" de modo general, esto es, sin delimitarlos expresamente a aquellos supuestos contemplados únicamente en la LP. Por tal motivo, perfectamente puede entenderse que las invenciones laborales no tan solo dicen relación con los títulos protegidos en la LP, sino también con cualquiera otro contenido en una ley diferente.

\section{1) Invenciones Patentables}

Una invención es patentable cuando reúne los requisitos de patentabilidad exigidos en el párrafo $1^{\circ}$ del artículo 4.1 LP. De este modo, "son patentables las invenciones nuevas, que impliquen actividad inventiva y sean susceptibles de aplicación industrial, aun cuando tengan por objeto un producto que esté compuesto o que contenga materia biológica, o un procedimiento mediante el cual se produzca, transforme o utilice materia biológica". Se considera que una invención es nueva "cuando no está comprendida en el estado de la técnica" (artículo 6.1 LP), entendiéndose que este estado "está constituido por todo lo que antes de la fecha de presentación de la solicitud de patentes se ha becho accesible al público en España o en el extranjero por una descripción escrita u oral, por una utilización o por cualquier otro medio". Asimismo, se establece que una invención implica una actividad inventiva "si aquella no resulta del estado de la técnica de una manera evidente para un experto en la materia" (artículo 8.1 LP).

En lo referido a la susceptibilidad de aplicación industrial se prescribe que la invención cumple tal exigencia "cuando su objeto puede ser fabricado o utilizado en cualquier clase de industria, incluida la agrícola" (artículo 8.1 LP).

Por último, la LP detalla una serie de supuestos que no son patentables, a saber:

a) Por estar apartados del concepto de invención: los descubrimientos, las teorías científicas y los métodos matemáticos; las obras literarias o artísticas o cualquier otra creación estética, así como las obras 
científicas; los planes, reglas y métodos para el ejercicio de actividades intelectuales, para juegos o para actividades económico-comerciales, así como los programas de ordenadores; las formas de presentar informaciones (artículo $4.4 \mathrm{LP}$ ).

b) $\mathrm{Al}$ no considerarse invención susceptible de aplicación industrial: los métodos de tratamiento quirúrgico o terapéutico del cuerpo humano o animal, ni los métodos de diagnósticos aplicados al cuerpo humano o animal. En todo caso, esta exclusión no se aplica a los productos, especialmente a las sustancias o composiciones, ni a las invenciones de aparatos e instrumentos para la puesta en práctica de tales métodos (artículo 4.6 LP).

c) Por disponerse que no pueden ser objeto de patente: las invenciones cuya exploración comercial sea contraria al orden público o a las buenas costumbres ${ }^{11}$ (artículo 5.1); las variedades vegetales y las razas animales (artículo 5.2); los procedimientos esencialmente biológicos de obtención de vegetales o de animales (artículo 5.3); el cuerpo humano, en los diferentes estadios de su constitución y desarrollo, así como el simple descubrimiento de uno de sus elementos, incluida la secuencia parcial de un gen (artículo 5.4).

\section{2) Modelos de utilidad}

También le es aplicable el régimen de invenciones laborales a los modelos de utilidad. Esta afirmación no solo se desprende del artículo 19 LP, según veíamos, sino también del artículo 154 LP, a cuyo tenor, "en defecto de norma expresamente aplicable a los modelos de utilidad, regirán para estos las disposiciones establecidas en la presente Ley para patentes de invención (...) entre otras, les serán aplicables las normas contenidas en el Título IV sobre invenciones laborales".

Serán protegibles como modelos de utilidad las invenciones "que siendo nuevas e implicando una actividad inventiva, consisten en dar a un objeto una configuración, estructura o constitución de la que resulte alguna ventaja prácticamente apreciable para su uso o fabricación" (artículo 143.1 LP). A título meramente ejemplar, se indica que pueden protegerse como modelos de utilidad "los utensilios, instrumentos, herramientas, aparatos, dispositivos o partes de los mismos, que reúnan los requisitos enunciados en el apartado anterior" (artículo 143.2 LP). No es posible comprender dentro de esta

Particularmente se encuentran incluidos en este orden: los procedimientos de clonación de seres humanos, procedimientos de modificación de identidad genética germinal del ser humano, utilización de embriones humanos con fines industriales o comerciales, procedimientos de modificación genética de los animales que supongan para estos sufrimientos sin utilidad médica o veterinaria sustancial para el hombre o el animal, y los animales resultantes de tales procedimientos (artículo $5.1 \mathrm{LP}$ ). 
categoría "las invenciones de procedimiento y las variedades vegetales" (artículo 143.3 LP).

\section{3) Adiciones}

Las adiciones consisten en invenciones que perfeccionan o desarrollan otra principal, siempre que se integren con el objeto de esta última en una misma unidad inventiva. Estas adiciones gozan de protección al igual que la invención original (artículo 108 LP). Del mismo modo que los modelos de utilidad, también le es aplicable el régimen de invenciones laborales.

Debe precisarse que esta categoría persigue el perfeccionamiento o desarrollo de algo ya existente, por lo que no es necesario que el objeto de la adicción implique una actividad inventiva frente al objeto de la patente principal. Luego, la primera se considerará parte integrante de la última (artículo 109 LP).

\section{4) Otros títulos de protección exclusiva}

El artículo 19.1 LP dispone que podrán ser reclamadas por el empresario como invenciones laborales para aquellas que se presente una solicitud de patente o de otro título de protección exclusiva. Según indicábamos, algunos autores estiman que solo pueden ser invenciones de esta clase aquellos títulos contemplados expresamente en la LP. En cambio, otros autores ${ }^{12}$ afirman que es posible entender como invención laboral otras creaciones asimilables a las invenciones pero protegibles por títulos de protección exclusiva no regulados en la LP, como son las obtenciones vegetales, las topografías de productos semiconductores y obras de propiedad intelectual, como programas de ordenador. Conviene destacar que respecto de los dos primeros (obtenciones vegetales y topografías de productos semiconductores), sus leyes ordenadoras en materia de invenciones laborales se remiten expresamente al Título IV de la LP13.

También debieran incluirse dentro de esta clase de títulos los diseños industriales ${ }^{14}$, regulados en la Ley 20/2003, de 7 de julio. Precisamente, el artículo 15 de la citada ley trata de los diseños creados en el marco de una relación de empleo o de servicios, materia que posteriormente examinaremos.

12 Vid. Lois Bastidas, Fátima: La protección del inventor asalariado, Civitas, Madrid, 2000, p. 67.

13 Cfr. Arrículo 10.5 Ley $N^{\circ} 3 / 2000$, de 7 de enero, de Protección de Variedades Vegetales; Artículo 3.2.a) Ley $\mathrm{N}^{\circ} 11 / 1988$, de 3 de mayo, de Protección Jurídica de las Topografías de los Productos Semiconductores.

14 Antes regulados en calidad de modelos y dibujos industriales en el Capítulo III del Estatuto de la Propiedad, aprobado por Real Decreto-Ley 26 de julio de 1929. 


\section{B. Ámbito Subjetivo}

\section{1) Relación laboral}

El régimen general establecido en el Título IV de Ia LP se aplica a las invenciones realizadas por personas vinculadas a la empresa por un contrato o relación de trabajo (artículo 15.1), de lo cual se desprende la laboralidad de esta clase de invenciones. Así, se someten a este régimen las partes de la relación laboral que, de acuerdo a lo dispuesto en las normas del Derecho del Trabajo, son los empleadores y los trabajadores por cuenta ajena, entendiéndose por estos últimos aquellos que voluntariamente presten sus servicio retribuidos por cuenta ajena y dentro del ámbito de organización y dirección de otra persona física o jurídica, denominada empleador o empresario (artículo 1.1 ET). Por su parte, han de ser considerados como empresarios todas las personas físicas o jurídicas, o comunidades de bienes que reciban la prestación de servicios de los trabajadores por cuenta ajena (artículo 1.2 ET).

Para la observancia de esta normativa se requiere que esté vigente el contrato o relación de trabajo en el momento en que la invención sea realizada. Por tanto, para calificar una invención como laboral, tanto el trabajador que la genera como el empleador han de encontrarse en condición de tales al momento en que esta se produce. En el caso de existir una relación de hecho en la que un sujeto presta un servicio retribuido por cuenta ajena y dentro del ámbito de organización y dirección de otro, ha de presumirse, según al artículo $8^{\circ}$ ET la existencia de un contrato de trabajo, con lo que en principio también resulta aplicable el régimen sobre invenciones laborales ${ }^{15}$.

\section{2) Relación de servicios}

Surge la duda acerca de si se comprende dentro de esta preceptiva, las personas vinculadas con una empresa por una relación de servicios (no sometida a la legislación laboral), debido al contenido del artículo 15.1 LP, que se refiere también a las invenciones realizadas por el trabajador "durante la vigencia (...) de relación de servicios con la empresa". Al respecto, parte de la doctrina ${ }^{16}$ es partidaria que el régimen en cuestión se encuentra circunscrito a las invenciones realizadas por los trabajadores, de manera que la relación o contrato que liga a estos con el empresario debe ser exclusivamente de naturaleza laboral. En este sentido, el antes denominado Registro de la Propiedad Industrial, hoy, Oficina Es-

15 Blanco Jiménez, Araceli: (n, 3), p. 87.

16 Estupiñán CÁceres, Rosalía: (n. 6), p. 155. 
pañola de Patentes y Marcas, indicó que solo debían considerarse invenciones laborales, a los efectos de la LP, las que resultan precisamente de un contrato de trabajo, principalmente debido a que no sería posible concebir una relación de servicios continuada con un empresario, sin que se aprecie un fraude de ley y se declare que en realidad dicha relación es de naturaleza laboral ${ }^{17}$.

En contrapartida, otros autores ${ }^{18}$ estiman que la ley no exige de manera exclusiva un contrato de trabajo para que exista una invención laboral, sino que también se admite que una relación de servicios (no sometida a la legislación laboral) pueda originar una invención de este género, ya que del artículo 15.1 LP se deduce que esta clase de invenciones abarca por igual al trabajador propiamente dicho, que presta sus servicios exclusivamente en la empresa, que al contratado en régimen de arrendamientos de servicios. Por tal motivo, se cricica la terminología tradicionalmente adoptada por el legislador en la materia, especialmente la propia expresión laboral que figura como rótulo del Título IV LP, así como la de trabajador, mostrándose preferencia por la de empleado, por traducir mejor esta tanto la relación de trabajo como la de prestación de servicio $^{19}$. En este orden, se apunta la conveniencia de referirse de manera genérica al contrato sin calificarlo como laboral ${ }^{20}$.

Luego, esta relación de servicios puede corresponder a un contrato de arrendamiento de servicios o de obra. A través del arrendamiento de servicios, una parte se obliga para con otra a realizar determinadas actividades, tales como el desarrollo de investigaciones, a cambio de una contraprestación. Por su parte, en el arrendamiento de obra una parte se obliga hacia la otra a cambio de una contraprestación a ejecutar una obra, la cual puede ser de carácter inmaterial, consistiendo perfectamente en el logro de una invención ${ }^{21}$.

\section{3) Relación laboral especial. Alto directivo}

Anteriormente, durante la vigencia de la LCT se entendían como invenciones laborales únicamente aquellas obtenidas por trabajadores por cuenta y dependencia ajena, excluyéndose de esta forma a los altos directivos de la empresa y los funcionarios públicos. Esta situación cambia a partir de la vigencia de la LP, resultando aplicable el régimen en cuestión

Vid. Lema Devesa, Carlos: (n. 1), p. 148.

Ibid., p. 149.

LoIS BASTIDAS, Fátima: (n. 12), p. 107.

Vid. Gomez Segade, José Antonio: "Derecho a la patente", en Fernández NovoA, C. y Gómez Segade, J. A.: La modernización del Derecho Español de Patentes, Montecorvo, Madrid, 1984, p. 120.

21 Blanco Jiménez, Araceli: (n.3), pp. 92-93. 
a los sujetos vinculados por una relación laboral especial, contenidas en el arrículo 2 ET, entre los cuales se encuentra el personal de alta dirección, regidos por el RD 1382/1985. Sobre este punto, debe recordarse que este personal constituye un colectivo vinculado a la actividad investigadora, ya que suele estar integrado por individuos de elevada cualificación y formación técnico profesional ${ }^{22}$.

Es necesario clarificar que no se incluyen en la situación anterior (invenciones laborales) a quienes ostentan los cargos de consejeros o miembros de los órganos de administración de empresas, ya que dichas personas quedan excluidas de las normas laborales, en virtud del artículo 1.3 c) ET. Dicha exclusión se fundamenta porque no concurre uno de los elementos característicos del contrato de trabajo, esto es, la subordinación. A su vez, también muchas veces está ausente la nota de ajenidad ${ }^{23}$.

\section{4) Funcionarios públicos}

Según veíamos, mientras regía la LCT solo podían considerarse como invenciones laborales a aquellas realizadas por trabajadores dependientes. De este modo, estaban apartados de dicha regulación los funcionarios públicos y demás personal al servicio de entes públicos. En su momento, esta situación fue criticada, ya que un amplio sector de la actividad investigadora carecía de regulación legal ${ }^{24}$.

Actualmente, si bien de acuerdo al ET los funcionarios públicos y en general la dotación de distintas administraciones públicas quedan fuera de la legislación laboral, en materia de invenciones laborales reciben el mismo tratamiento que un trabajador dependiente, al no concurrir en esta materia las razones que justifican la exclusión indicada ${ }^{25}$. Por tal motivo, el artículo $20.1 \mathrm{LP}$ prescribe que las normas del presente Título serán aplicables a los funcionarios, empleados y trabajadores del Estado, Comunidades Autónomas, Provincias, Municipios y demás Entes Públicos. Lo anterior

22 BERCOVITZ, Alberto: "Anotaciones a la regulación legal española sobre invenciones laborales", en Actas de Derecho Industrial, 1976, p. 58.

23 De acuerdo con el artículo $1^{\circ} \mathrm{ET}$, el vínculo laboral se configuraría cuando voluntariamente se presten servicios retribuidos por cuenta ajena y dentro del ámbito de organización y dirección de otra persona, física o jurídica, denominada empleador o empresario. Por tanto, se requiere la confluencia de 4 elementos, a saber: a) voluntariedad, pues debe tratarse de una actividad realizada de manera libre, previa manifestación de consentimiento; b) ajenidad, es decir que, los frutos del trabajo, o su utilidad económica son aprovechados por quien contrata los servicios; c) dependencia o subordinación, lo cual se desprende de la exigencia que los servicios se presten "dentro del ámbito de organización y dirección de otra persona", ya el trabajo asalariado se realiza únicamente bajo las órdenes e instrucciones de otra persona; y d) retribución, tal es que la prestación de servicios debe ser correspondida por una contraprestación de contenido económico.

24 Bercovitz, Alberto: (n. 22), p. 58.

25 Sala Franco, Tomás y Otros: Derecbo del Trabajo, Tirane Lo Blanch, Valencia, 1995, p. 233. 
se traduce en un principio de igualdad entre las invenciones que se producen en los sectores privado y público ${ }^{26}$.

Finalmente, debemos indicar que los profesores de Universidad y personal investigador tienen un régimen especial contemplado en la propia LP.

\section{Profesores de Universidad y personal investigador de entes pú- blicos de investigación}

Como mencionábamos, la LP contiene una normativa específica para las invenciones logradas por los profesores universitarios y personal investigador de los Centros Públicos de Investigación.

De conformidad con los párrafos 2 a 7 del artículo 20 LP, se establece que pertenece a la Universidad la titularidad de las invenciones realizadas por el profesor como consecuencia de su función de investigación en la Universidad y que pertenezcan al ámbito de sus funciones docente e investigadora (artículo 20.2). El profesor tendrá derecho a participar en los beneficios que obtenga la Universidad de la explotación o de la cesión de sus derechos sobre las invenciones mencionadas, corresponderá a los Estatutos de la Universidad determinar las modalidades y cuantía de esta participación (artículo 20.4). Se contempla la posibilidad de que la Universidad pueda ceder la titularidad de las invenciones al profesor, autor de las mismas, pudiendo reservarse en este caso una licencia no exclusiva, intransferible y gratuita de explotación (artículo 20.5). En estos casos, si el profesor obtiene beneficios de la explotación de una invención, la Universidad tendrá derecho a una participación en los mismos determinada por los Estatutos de la Universidad (artículo 20.6).

Asimismo, se consigna que si un profesor realiza una invención como consecuencia de un contrato con un ente privado o público, el contrato deberá especificar a cuál de las partes contratantes corresponderá la titularidad de la misma (artículo 20.7).

Por último, se señala que el régimen antes detallado podrá aplicarse a las invenciones del personal investigador de entes públicos de investigación. Las modalidades y cuantía de la participación del personal invesrigador de estos entes en los beneficios que se obtengan de la explotación o cesión de sus derechos sobre las invenciones mencionadas serán establecidas por el Gobierno, atendiendo a las características concretas de cada ente de investigación (artículos 20.8 y 20.9). No obstante lo anterior, hasta el momento no existe reglamentación alguna al respecto ${ }^{27}$. 


\section{ClASIFICACIÓN DE INVENCIONES LABORALES}

La LP distingue tres categorías de invenciones laborales, las que no reciben una denominación específica, a diferencia de lo que ocurría con la LCT. De todas modos, parte de la doctrina ${ }^{28}$ las ha designado de la siguiente forma: invenciones de servicios, invenciones mixtas y las invenciones libres ${ }^{29}$.

A continuación examinaremos cada una de ellas.

\section{A. Las invenciones de servicios}

\section{1) Concepto}

De acuerdo al artículo 15.1 LP las invenciones de servicios o invenciones laborales propiamente tales ${ }^{30}$ son aquellas "realizadas por el trabajador durante la vigencia de su contrato o relación de trabajo o de servicios con la empresa, que sean fruto de una actividad de investigación explícita o implícitamente constitutiva del objeto de su contrato".

Es posible apreciar que estas invenciones constituyen el resultado de una actividad investigación para cuya obtención, de forma expresa o no, exclusiva o no, fue contratado el trabajador. Así, podemos señalar que son aquellas susceptibles de ser amparadas por un título de protección exclusiva que, habiendo sido realizadas por el trabajador durante la vigencia de su contrato o relación laboral, constituyan el fruto de una actividad de investigación para cuya consecución fue contratado el inventor ${ }^{31}$.

De acuerdo a lo expuesto, la invención es la causa del contrato de trabajo $^{32}$, e intentar inventar es su objeto ${ }^{33}$. En este sentido, debe recalcarse que el invento no es el objeto contractual, ya que en la investigación no puede asegurarse resultados concretos, por lo cual cuando se contrata a alguien para que realice esta labor, se espera que razonable-

28 Sala Franco, Tomás y ViCent Chuliá, Francisco: "El nuevo régimen jurídico de las invenciones laborales", en Actualidad Laboral $\mathrm{N}^{\circ} 4,1988$, p. 1985. Del mismo modo, FEAS Costillas, Javier: "Las invenciones laborales en la Ley de Patentes de 1986", en Revista del Trabajo, $\mathrm{N}^{\circ}$ 87, 1987, p. 127; BlAnCO J1MÉnEz, Araceli: (n. 3), p. 97. Conviene precisar que otros autores utilizan otras clasificaciones, así Alonso Olea distingue entre invenciones de servicios, artículo $15 \mathrm{LP}$; invenciones de explotación, artículo 17 LP; e invenciones libres, artículo 16 LP (AlONSO OLEA, Manuel y CASAS BAAMONDE, María Emilia: Derecho del Trabajo, Civitas, Madrid, 1997, p. 307). Lema Devesa las cataloga en invenciones de encargo, artículo 15 LP; invenciones dependientes, artículo 17 LP; e invenciones libres, artículo 16 (LEMA DEveSA, Carlos: (n. 1), p. 149).

Ibid.

ESTUPiÑán CÁCERes, Rosalía: (n. 6), p.73.

Alonso Olea, Manuel y Casas BaAmonde, María Emilia: (n. 28), p. 306.

Ibid. 
mente de dicha actividad se deriven invenciones ${ }^{34}$. Es decir, lo que se pacta es una obligación de investigar y no de obtener invenciones.

En resumen, este tipo de invención laboral se caracteriza por la presencia de dos elementos: la previsión de la actividad investigadora como objeto del contrato; y la obtención de la invención en el ejercicio y como resultado de dicha actividad contractualmente debida. Sobre este último punto, parte de la doctrina ${ }^{35}$ sostiene que dada la inclusión del término "implícito" basta que la actividad laboral del trabajador, en todo o parte, sea de investigación o experimentación susceptible de conseguir esa innovación, pero sin necesidad de haber sido contratado exclusivamente para ello, ni tampoco que se hubiere asignado la consecución de tal resultado. No se excluye, por tanto, un cierto margen de iniciativa en el propio inventor. En cambio otros tratadistas ${ }^{36}$ opinan que no es suficiente haber recibido una misión de investigación, sino que además la invención debe realizarse en estricto cumplimiento del encargo, ya que según el artículo 15.1 LP, estas invenciones deben ser fruto de la actividad de investigación. Lo anterior plantea el problema de determinar cuándo una invención resulta precisamente de la actividad pactada con el trabajador. En este orden, por un lado, se deberá probar la realidad de la misión investigadora y, de otro, verificar la correspondencia efectiva entre esta y la invención.

Finalmente, la invención ha de ser desarrollada durante la vigencia del contrato de trabajo ${ }^{37}$. Incluso, algunos autores ${ }^{38}$ consideran que dicho período debe coincidir con el momento en el cual se desarrolla la parte decisiva de la investigación y no la parte terminal de ella.

\section{2) Titularidad}

La titularidad de esta clase de invenciones constituye una excepción a la regla general que otorga los derechos patrimoniales de una invención a su inventor ${ }^{39}$, ya que en estos casos estas pertenecen al empresario sin restricciones de ningún tipo, como fruto industrial cuya atribución se realiza ex lege desde el mismo momento de su producción y sin que jamás el inventor haya sido propietario de la misma ${ }^{40}$. En efecto, como en todo trabajo por cuenta ajena, de los resultados de la actividad del trabajador lucra la otra parte del contrato, es decir, el empresario ${ }^{41}$.

34 Gómez Segade, José Antonio: (n. 20), pp. 120-121.

35 Rodríguez Piñero, Miguel: "El nuevo régimen jurídico de las invenciones laborales", en Relaciones Laborales, $\mathrm{N}^{\circ} 6,1986$, p. 45.

LOIS BASTIDAS, Fátima: (n. 12), p. 133.

Vid. Sala Franco, Tomás y Vicent Chulí, Francisco: (n. 28), p. 1985.

Vid. Blanco Jiménez, Araceli: (n. 3), p. 98.

CFr. Artículo $10 \mathrm{LP}$.

Sala Franco, Tomás y Otros: (n. 25), p. 399.

Diéguez Cuervo, Gonzalo: Lecciones de Derecho del Trabajo, Marcial Pons, Madrid, 1995, p. 242. 
Lo anterior no es impedimento para que, según previene el artículo $14 \mathrm{LP}$, el inventor tenga, frente al titular de la solicitud de patente, el derecho a ser mencionado como tal, compatibilizándose así la propiedad y la titularidad a favor del empresario, con el derecho honorífico del inventor a que se le tenga en cuenta como $\mathrm{tal}^{42}$.

La atribución de dicha titularidad al empresario, supone la aceptación de la tesis de la adquisición originaria, directa o inmediata del invento por parte el empleador, como auténtico fruto industrial, sin necesidad de ningún acto dispositivo o atributivo posterior del trabajador. Así, la mejor calificación que corresponde a las invenciones de servicios es la de frutos industriales; debe recordarse que estos son los producidos por predios de cualquier especie a beneficio del cultivo o del trabajo, cuya titularidad pertenece al propietario de la empresa ${ }^{43}$. En este ámbito, dado que de las obligaciones del trabajador se destaca principalmente la prestación identificada con el esfuerzo para alcanzar invenciones, resulta razonable que esta pertenezca al empresario ${ }^{44}$.

\section{3) Remuneración del trabajador inventor}

\section{a) Regla general - No se genera remuneración extraordinaria}

En relación a la remuneración del inventor, se establece que, en principio, no se tendrá derecho a una remuneración suplementaria por el logro de un invento (artículo 15.2 LP). Lo anterior, se debe a que el trabajador fue contratado especialmente para tal efecto, de modo que la invención conforma una finalidad esperable de su actividad, no debiendo constituir fundamento para ningún tipo de remuneración suplementaria, ya que no sería lógico recompensar por efectuar lo que se ha contratado ${ }^{45}$.

En todo caso, nada obsta a que puedan estipularse, ya sea en el contrato individual de trabajo, o en un convenio colectivo, remuneraciones suplementarias para los trabajadores-inventores, con la finalidad de estimular la concreción de invenciones ${ }^{46}$.

\section{b) Excepción - Remuneración suplementaria}

Excepcionalmente, el trabajador tendrá derecho a una remuneración suplementaria, para lo cual tendrán que concurrir dos circunstancias, a saber: que la aportación personal a la invención y la importancia

42 Sala franco, Tomás y Otros: (n. 25), p. 399.

43 Albiol Montesinos, Ignacio: "Los inventos del trabajador, el socio industrial y la ejecución de obra", en Revista de Derecho Privado, 1975, p. 113.

44 Lema Devesa, Carlos: (n. 1), p. 150.

45 Gómez Segade, José Antonio: (n. 20), p, 123.

46 ESTUPIÑÁN CÁCERES, Rosalía: (n. 6), p.188. 
de la misma excedan de manera evidente el contenido explícito o implícito del contrato (artículo 15.2 LP).

Sobre la primera de ella, esta es "que la aportación personal a la invención exceda de manera evidente el contenido explícito o implícito de su contrato", surge inmediatamente el problema acerca de cómo ha de valorarse dicha aportación, debido a que la LP no contempla ningún procedimiento al respecto. Luego, teniendo en cuenta que el trabajador está contratado para investigar, determinar cuándo esta es una consecuencia normal, o bien un exceso, resulta una operación bastante compleja, que puede ser fuente de litigio entre las partes.

En relación a la segunda circunstancia exigida, esta es que "la importancia de la invención exceda el contrato" en los términos antes mencionados, tampoco existe un parámetro para valorar este eventual exceso. A su vez, no se indica a qué clase de importancia se refiere. En este escenario, es perfectamente aplicable la conclusión anterior, relativa a la eventual generación de conflictos.

Sin perjuicio de lo anterior, conviene indicar que con respecto a la calificación de "la importancia de la invención", esta parece versar sobre una valoración económica ${ }^{47}$, ya que para la empresa el elemento de mayor importancia a considerar en una invención es el económico, en cualquier sentido que este se manifieste (abaratamiento de costos, procedimientos, etc.).

\section{c) Principio de compensación}

Es interesante constatar que de acuerdo a la LP, este derecho a la remuneración suplementaria, sigue el principio de la compensación en correspondencia a un resultado. Este sistema se ha cuestionado, manifestándose $^{48}$ que debería adoptarse el llamado principio de rentabilidad de la patente, según el cual esta retribución especial solo se atribuiría cuando la invención proporcione al empresario beneficios extraordinarios.

\section{d) Naturaleza de la remuneración}

En cuanto a la naturaleza de la remuneración suplementaria, por un lado, parte de la doctrina ${ }^{49}$ advierte que esta tiene un carácter salarial, tratándose de una específica atribución retributiva, a la que son aplicables las reglas sustantivas y adjetivas referidas al salario. En contrapartida, se indica ${ }^{50}$, que pese a la terminología legal, dicha remuneración

Vid. Rodríguez Piñero, Miguel: (n. 35), p. 45.

Lema Devesa, Carlos: (n. 1), p. 152.

Rodrf́guez Piñero, Miguel: (n. 35), pp. 46 - 47.

Sala Franco, Tomás y Vicent ChuliA, Francisco: (n. 28), p. 1986. 
tiene naturaleza extrasalarial. En esa dirección, el carácter civil de las normas reguladoras parece más acorde con la naturaleza indemnizatoria y, por tanto, extrasalarial de la remuneración complementaria; dada esta naturaleza, se entiende que, de haberse fijado una cuantía periódica en atención a los beneficios de la explotación, el trabajador va a seguir cobrando esta remuneración adicional una vez extinguido el contrato de trabajo.

\section{e) Determinación de la remuneración}

Esta remuneración suplementaria se fijará de común acuerdo por las partes, o en su defecto, se fijará el juez, previo trámite obligatorio ante la Comisión de Conciliación, previsto en el capítulo IV del Título XIII de la LP.

\section{B. Invenciones Mixtas}

\section{1) Concepto}

Esta clase invención laboral se encuentra desarrollada en el artículo 17 LP, entendiéndose por ella, la que realiza el trabajador "en relación con su actividad profesional", pero en cuya "obtención bubieran influido predominantemente conocimientos adquiridos dentro de la empresa o la utilización de medios proporcionados por esta". El empresario "tendrá derecho a asumir la titularidad de la invención o reservarse un derecho de utilización de la misma".

En este caso, en el orden conceptual se debe partir de la premisa que no concurran las circunstancias previstas en el artículo 15 LP (invención de servicios). De tal manera, se requiere que el trabajador no haya sido contratado para el desarrollo de actividades de investigación. Eso sí, la invención debe estar relacionada con la actividad profesional del trabajador en la empresa, por lo que ella debe ser fruto de los trabajos efectuados precisamente en la compañía. Al exigirse dicha relación (invención-actividad del trabajador), se excluyen las invenciones obtenidaś por el trabajador al margen de sus funciones en la empresa; esto es aquellas ajenas a su actividad profesional.

Asimismo, en la obtención de la invención deben converger uno de dos factores, alternativamente, a saber: que haya influido predominantemente los conocimientos que se hayan adquirido dentro de la empresa; o bien, la utilización de medios proporcionados por esta. La expresión "conocimientos" expresa la contribución intelectual de la empresa, integrada por informaciones, know-bow, prácticas, ideas obtenidas de conversaciones con compañeros de trabajo, y en definitiva, cualquier contribución inmaterial de estímulo intelectual. En tanto, el término "medios", expresa la contribución tecnológica derivada de la utilización de instrumentos, tales 
como ordenadores, microscopios, etc., sin los cuales la invención no hubiera podido ser realizada ${ }^{51}$. Conviene precisar que los medios proporcionados por la empresa deben ser elementos específicos; por eso, el hecho de utilizar materiales triviales o la biblioteca de la empresa no permite calificar la invención como dependiente ${ }^{52}$.

De lo expuesto, es posible deducir que la consecución de esta categoría de invención es de carácter extraordinario, ya que no forma parte del objeto del contrato la actividad investigadora ${ }^{53}$; pero sí, esta invención será generalmente resultado del desarrollo de la prestación laboral por parte del trabajador.

\section{2) Titularidad}

De un análisis del artículo 17 LP, es posible colegir que en estas invenciones la titularidad originaria pertenece al respectivo trabajador, lo cual implica que si la invención es adquirida por el empresario, esto será a título derivado, mediante el ejercicio del derecho a opción que le concede la ley, sin que se requiera la concurrencia de la voluntad del trabajador inventor ${ }^{54}$.

En este régimen de invenciones es el empresario el que decide la modalidad de utilización, pudiendo optar entre asumir la titularidad de la invención o reservarse el derecho de utilización de la misma ${ }^{55}$. En uno como en otro supuesto, el trabajador tiene derecho a una compensación económica justa que deberá tener en cuenta, de modo similar a las invenciones de servicios, la importancia industrial y comercial del invento y el valor de los medios o conocimientos facilitados por la empresa y las aportaciones propias del trabajador. El plazo de la asunción de estos derechos por parte del empleador es de tres meses desde que le fuera comunicada por el trabajador la existencia de la invención, de acuerdo a lo establecido en al artículo $18.1 \mathrm{LP}$.

Por su parte, es interesante constatar que se discute acerca de la naturaleza jurídica del derecho alternativo que se otorga al empresario. Algunos autores ${ }^{56}$ indican que partiendo de la base de que es una invención de iniciativa del trabajador, debería corresponder a este la titularidad de ella. Sin embargo, dadas las circunstancias de su realización (medios y conocimientos obtenidos de la empresa), se concede una opción, de clase "expropiatoria" al empresario, ya sea para asumir la titularidad de

LOIS BASTIDAS, Fátima: (n. 12), p. 145.

Vid. Lema Devesa, Carlos: (n. 1), p. 150.

BLANCO Jiménez, Araceli: (n. 3), p. 103.

LOIS BASTIDAS, Fátima: (n. 12), p. 169.

Sala Franco, Tomás y Otros: (n. 25), p. 400 ,

RodrfGuez PiN̂ERO, Miguel: (n. 35), p. 45. 
la invención, o bien, reservarse un derecho a la utilización, pero en uno y otro caso, compensado económicamente de forma justa esa obtención de titularidad o esa reserva a derecho de utilización. De esta manera, se distinguen de las invenciones de servicio, donde la pertenencia de la invención del empresario es originaria y automática ${ }^{57}$. Otro sector de la doctrina ${ }^{58}$ estima que, teniendo en cuenta que el derecho del empresario a asumir la titularidad de la invención juega independientemente de la voluntad del trabajador, dicha prerrogativa se identifica con un derecho real que opera, al margen de vicisitudes contractuales, sobre la invención, más que a un derecho de obligaciones.

Ahora bien, lo que no ofrece dudas en esta materia es que el legislador se ha inclinado a favor del interés del empresario. Lo anterior, ha sido objeto de críticas, que advierten que dicha atribución contradice de forma innecesaria el principio general reconocido en el Derecho de Patentes, por el cual este derecho debe corresponder al inventor, ya que todo esfuerzo lo realiza el trabajador y la ley solo le fija una compensación que es difícil de fijar ${ }^{59}$.

Finalmente, es necesario señalar que el trabajador tendrá derecho (como en las invenciones de servicios) a ser mencionado como inventor en la patente, si el empresario opta por asumir la titularidad de la invención.

\section{3) Compensación económica del trabajador inventor}

Tal como indicábamos, tratándose de esta clase de invención laboral, si el empresario asume la titularidad del invento o se reserva un derecho de utilización sobre el mismo, surge el derecho para el trabajador a una compensación económica justa (artículo 17.2 LP). Al respecto, dicha norma establece que "el trabajador tendrá derecho a una compensación económica justa, fijada en atención a la importancia industrial y comercial del invento y teniendo en cuenta el valor de los medios o conocimientos facilitados por la empresa y las aportaciones propias del trabajador".

De este modo, para que el empleador deba compensar al trabajador es necesario que el primero ejercite el derecho alternativo que le otorga la ley, de lo contrario el titular de la invención vendría a ser el trabajador. En esta línea, la mencionada compensación se decanta como la contrapartida directa de la obtención del empresario de todo o parte de los derechos patrimoniales derivados de la invención ${ }^{60}$.

A su vez, es posible constatar que la compensación en cuestión no tiene naturaleza salarial. Pues este pago no va dirigido a retribuir la

Ibid. 46 .

Vid. LOIS BASTIDAS, Fátima: (n. 12), p. 165.

GÓmez Segade, José Antonio: (n. 20), p, 122.

Vid. Estupiñán Cáceres, Rosalía: (n, 6), p. 205. 
prestación de los servicios profesionales por cuenta ajena, según lo dispuesto en el artículo 26.1 ET, sino más bien se trata de un precio que el empresario está abonando para reservarse la titularidad de la invención, que originariamente no le pertenece. Así, se manifiesta ${ }^{61}$ que tal compensación tiene una ratio indemnizatoria.

\section{Invenciones Libres}

Esta categoría dice relación con invenciones pertenecientes al trabajador, no reconociéndose a la empresa ningún derecho sobre ellas. No se encuentran definidas en la LP, derivándose su delimitación de un análisis conjunto de los artículos 15, 16 y $17 \mathrm{LP}$, de este modo se alcanza un concepto negativo de este tipo de invenciones.

Sobre el particular, puede decirse que pertenecen a este tipo de invenciones aquellas no incluidas en los grupos anteriores, en las que predomina la personalidad e inventiva del trabajador $^{62}$. Luego, debe tratarse de invenciones realizadas por trabajadores durante la vigencia del contrato, la cuales no sean el resultado de una actividad de investigación explícita o implícita contratada, o bien, que en su logro no hayan influido de forma predominante conocimientos o medios proporcionados por la empresa. Asimismo, también pertenecerán a este tipo, las que reuniendo las características de las invenciones mixtas (artículo 17.1), queden liberadas porque el empresario no ejerce su derecho a opción ${ }^{63}$.

Como indicábamos, la titularidad de estas invenciones corresponde al trabajador, autor de la misma. Es interesante constatar que a diferencia de lo que ocurría con las otras categorías, al trabajador no se le impone la obligación de comunicar su logro al empresario, que como veremos se exige en las categorías antes tratadas. No obstante, algunos autores ${ }^{64}$ señalan que, sobre la base del deber de fidelidad del trabajador, existe "una cierta obligación de ofrecer en primer lugar la explotación del invento al empresario estando a cuyo servicio la invención ocurrió, en el supuesto de que haya nacido con motivo de su actividad". En contraposición a esta postura, se indica ${ }^{65}$ que el deber de fidelidad no puede ser entendido tan ampliamente, haciendo surgir en el trabajador una obligación que la LP no contempló, aun más la STS de 28 de diciembre de 1959 (en que se basa el autor anterior) parte de supuestos de hecho que hoy podrían encuadrarse en la invenciones mixtas.

Sala franco, Tomás y Vicent Chuliá, Francisco: (n. 28), p. 1987.

Vid. Alonso Olea, Manuel y Casas BaAmonde, María Emilia: (n. 28), p. 307.

ESTUPIÑÁN CÁCERES, Rosalía: (n. 6), p. 211.

Alonso Olea, Manuel y CASAs BaAmonde, María Emilia: (n. 28), p. 307.

Feas Costillas, Javier: (n. 28), p. 129. Del mismo modo, Estupiñán Cáceres, Rosalía: (n. 6), pp. $212-213$. 
Finalmente, es posible verificar que en realidad esta clase invenciones no son propiamente laborales, por cuanto se producen sin relación con la condición de asalariado, razón por la cual pertenecen libremente al trabajador.

\section{DEBERES Y DERECHOS EN EL RÉGIMEN DE INVENCIONES LABO- RALES}

\section{A. El deber de información}

El trabajador que realice alguna de las invenciones de servicios y mixtas, deberá informar de ello al empresario, mediante comunicación escrita, con los datos e informes necesarios sobre la invención llevada a cabo (artículo 18.1 LP). Tal como antes indicábamos, se excluyen expresamente las invenciones libres.

La consecuencia del incumplimiento de esta obligación es la pérdida de los derechos que la normativa en cuestión reconoce al trabajador. Esta sanción se establece a modo de cláusula penal que pretende evitar fraudes y ocultaciones al respecto. Sin embargo, la rigidez de la norma puede ocasionar que en muchos casos sea desproporcionada dicha consecuen$\mathrm{cia}^{66}$.

Por su parte, en la mencionada disposición se establece un plazo de tres meses para que el empresario pueda ejercitar los derechos que le corresponden. El período de tres meses comenzará a contarse, no desde la fecha del invento sino desde la fecha de la notificación del mismo empresario ${ }^{67}$. Este plazo no debe entenderse referido a las invenciones de servicios, pues estas se atribuyen directamente al empresario, pudiendo este solicitar su patente cuando lo estime conveniente, sin límite de tiempo. En conclusión, este ejercicio de derechos dice relación con las invenciones mixtas.

Luego, si cumplido correctamente el requisito de información, el empresario no asume la titularidad de la invención ni se reserva un derecho a utilizarla, el trabajador podrá patentarla ${ }^{68}$.

\section{B. El deber de colaboración}

Tanto el empresario como el trabajador deberán prestar su colaboración en la medida necesaria para la efectividad de los derechos reconocidos en el presente régimen, absteniéndose de cualquier actuación que

\footnotetext{
66 Vid. Rodrfguez Piñero, Miguel: (n. 35), p. 47.

67 Sala Franco, Tomás y Vicent Chuliá, Francisco: (n. 28), p.1988.

68 Feas Costillas, Javier: (n. 28), p. 133.
} 
pueda redundar en detrimento de tales derechos (artículo 18.2 LP). Se trata de una manifestación del genérico deber de buena fe contractual de los artículos 7.1 y 1258 CC o del más específico que aparece en los artículos 5 a), 20.2 y 54.2 d) $\mathrm{ET}^{69}$.

Esto significa para el trabajador que debe aportar todos los datos que posea sobre la invención y prestar su colaboración para solicitar el correspondiente título de protección exclusiva. Por su lado, el empresario ha de cooperar para que el trabajador pueda hacer efectivo los derechos que le atribuye la ley, tales como el derecho a recibir una remuneración o compensación económica por el invento realizado ${ }^{70}$.

Con respecto a la obligación de abstención señalada, se afirma ${ }^{71}$ que de esta se deriva la necesaria discreción y sigilo del hecho inventivo que las partes deben observar, esto es, el deber de secreto. Este deber resulta imprescindible, ya que darse a conocer la invención a personas extrañas destruye la novedad, que es un requisito básico para obtener la patente.

\section{La reclamación del empresario}

El artículo 19.1 LP establece: "Las invenciones para las que se presente una solicitud de patente o de otro título de protección exclusiva dentro del año siguiente a la extinción de la relación trabajos o de servicios podrán ser reclamadas por el empresario". Esta disposición tiene por finalidad evitar el fraude que para los derechos e intereses del empresario supondría que el trabajador patentase una invención, que perteneciese a aquel, dada la normativa tratada. Es decir, esta reclamación tendrá por objeto, ya sea la invención de servicio, o bien la invención mixta ${ }^{72}$.

Sobre este punto, es interesante constatar que aquí no existe una presunción iuris tantum de que la invención sea de servicio o mixta, por el contrario, se entiende la presunción contraria, correspondiendo la carga de prueba al empresario que reclama la invención ${ }^{73}$.

\section{Renuncia de derechos}

Los derechos del trabajador contemplados en este régimen no pueden ser renunciados anticipadamente. Así lo prescribe el artículo 19.2, a saber: "Será nula toda renuncia anticipada del trabajador a los derechos que la Ley le otorga en este título". De este modo, se traslada a la invenciones laborales el principio general de Derecho del Trabajo (artículo 3.5 ET),

Vid. Sala franco, Tomás y Vicent Chulíá, Francisco: (n. 28), p. 1988.

BlanCO JIMÉNEZ, Araceli: (n. 3), p. 137.

Vid. LoIS BASTIDAS, Fátima: (n. 12), p. 242.

Rodríguez Piñero, Miguel: (n. 35), p. 47.

FeAs Costillas, Javier: (n. 28), p. 134. 
que establece que los trabajadores no podrán disponer de los derechos que se le reconozcan a través de normas de derecho necesario. Debe notarse que solo se prohíbe la renuncia anticipada, por lo que a contrario sensu supone posibilitar la renuncia a posteriori y recortar así el alcance genérico del artículo 3.5 ET, en esta materia ${ }^{74}$.

\section{E. Conciliación}

Los artículos 140 a 142 LP establecen un procedimiento de conciliación previo a la acción judicial basada en la aplicación judicial de las normas contempladas en el Título IV de la citada ley, sobre invenciones laborales, la cuestión discutida deberá ser sometida a un acto de conciliación ante el Registro de la Propiedad Industrial. Para estos efectos, se constituirá una Comisión presidida por un experto del Registro de la Propiedad Industrial designado por el Director de dicho organismo y formada por un experto designado por los trabajadores de la empresa a la que pertenezcan el inventor y otro experto designado por el empresario.

\section{F. Orden jurisdiccional}

El artículo 123 LP, dispone que: "El conocimiento de todos los litigios que se susciten como consecuencia de acciones, de cualquier clase y naturaleza que sean, derivadas de la aplicación de los preceptos de la presente ley, corresponde a los órganos de la Jurisdicción ordinaria". Dado el alcance general de esta norma, mayoritariamente se considera plenamente aplicable a las invenciones laborales ${ }^{75}$. Por tanto, el conocimiento de este tipo de materia es tarea de la jurisdicción ordinaria, quedando al margen la social.

\section{INVENCIONES LABORALES EN LOS DISEÑOS INDUSTRIALES}

Según manifestábamos el artículo 15 de la LDI, atiende a los diseños creados en el marco de una relación de empleo o de servicios, estableciéndose que "cuando el diseño haya sido desarrollado por un empleado en ejecución de sus funciones o siguiendo las instrucciones del empresario o empleador, o por encargo en el marco de una relación de servicios, el derecho a registrar el diseño corresponderá al empresario o a la parte contractual que baya encargado la realización del diseño, salvo que en el contrato se disponga otra cosa".

74 Sala Franco, Tomás y Otros: (n. 25), p. 402.

75 Alonso Olea, Manuel y Casas BaAmonde, María Emilia: (n. 28), p. 307; Sala FranCO, Tomás y Otros: (n. 25), p. 402; FeAs Costillas, Javier: (n. 28), p. 135 . En posición contraria, sosteniendo que corresponde a la jurisdicción social el conocimiento de esta clase de asuntos, Rodrf́guez Piñero, Miguel: (n. 35), p. 42. 
En este caso a diferencia de lo tratado en la LP, se establece expresamente que la actividad inventiva puede ser objeto de un contrato de trabajo o de prestación de servicios, dejándose de lado las dudas que sobre esta materia se generan en dicha ley. Asimismo, parece ser que el único supuesto contemplado por artículo detallado es el de las invenciones de servicios, ya que se trata de labores desarrollas por un empleado ${ }^{76}$ cumpliendo funciones o instrucciones derivadas de un contrato de trabajo o prestación de servicios.

En este sentido, surge la duda sobre si también en este caso se aplican la normas de LP, especialmente lo referido a las invenciones mixtas y libres, como a su vez el régimen de derechos y obligaciones. Al respecto, debe tenerse en consideración que la LDI no se remite en esta materia al título IV de la LP, únicamente, en su disposición adicional primera, se refiere a dicha ley, entre otras cosas, para consignar que no le serán aplicables las disposiciones de Conciliación en materia de invenciones laborales. En todo caso, la solución a la problemática planteada dependerá, según veíamos, de la postura que se adopte, con respecto al término título de protección exclusiva utilizado en el artículo 19.1 LP. Según apuntábamos, nuestra posición es que dicha regulación también abarca invenciones que pueden ser protegibles por otras modalidades de Propiedad Industrial (no incluidas en la LP), por tanto, tal preceptiva sería aplicable al diseño industrial. A mayor abundamiento, la LDI prescribe expresamente que no serán observadas ciertas disposiciones de la LP, no incluyéndose en este listado las normas sustantivas sobre invenciones laborales.

\section{REgulación de LAS INVENCIONES LABORALES EN CHILE}

En Chile las invenciones laborales se encuentran regladas en la Ley $\mathrm{N}^{\circ} 19.039$, de 25 de enero de 1991, que establece normas aplicables a los Privilegios Industriales y protección de los derechos de Propiedad Industrial, y en su Reglamento aprobado por el Decreto Supremo $N^{\circ} 177$ de 6 de mayo de 1991. De este modo, se adopta el mismo criterio que en España consistente en disciplinar este tema en la legislación sobre propiedad industrial. Estas invenciones se contienen en el Título VI de la citada Ley, bajo el rótulo "De las invenciones de servicio". Se trata de una regulación, salvo determinados aspectos, bastante similar a la normativa española, según veremos a continuación.

Parece ser que se opró por la expresión empleado, y no trabajador, por considerarse la primera de mayor amplitud, pudiendo ser relacionada con relaciones de prestación de servicios civiles. 
Previamente, conviene indicar que en la ley chilena también se distinguen las tres clases de invenciones antes examinadas (aunque no reciban dicha denominación expresamente), estas son: invenciones de servicios, mixtas y libres. Precisamente, nos basaremos en esta clasificación, para facilitar la comprensión de los principales puntos de esta normativa, a saber:

\section{A. Invenciones de servicios}

Estas invenciones se desarrollan en el artículo 68 de la citada ley, cuyo tenor dispone que "en los contratos de trabajo y prestación de servicios, cuya naturaleza sea el cumplimiento de una actividad inventiva o creativa, la facultad de solicitar el privilegio así como los eventuales derechos de propiedad industrial, pertenecerán exclusivamente al empleador o a quien encargó el servicio, salvo estipulación expresa en contrario".

\section{1) Titularidad}

Dado que se trata de invenciones de servicios se establece que su titularidad pertenece al empleador o a quien encargó la actividad inventiva, indicándose que les corresponderá exclusivamente "la facultad de solicitar el privilegio 77 así como los eventuales derechos de propiedad industrial"78. Tal como en el caso español, la atribución de dicha titularidad al empresario, supone la aceptación de la tesis de la adquisición directa por parte de este del invento, sin que se requiera un acto dispositivo posterior del trabajador.

\section{2) Contrato de trabajo o de prestación de servicios}

Como se aprecia, se establece expresamente que dicha invención puede ser consecuencia de un contrato de trabajo, o de una relación de prestación de servicio. Al respecto, conviene destacar que no se utiliza el término "trabajador"; como a su vez, no solo se hace referencia al "em-

\footnotetext{
77 El artículo $1^{\circ}$ de la Ley $\mathrm{N}^{\circ} 19.039$ establece que los referidos privilegios comprenden las marcas comerciales, las patentes de invención, los modelos de utilidad, los diseños industriales y otros títulos de protección que la ley pueda establecer.

78 Conviene indicar sobre este punto, que el Reglamento, en su artículo 111 reitera que "Los derechos de propiedad industrial derivados del trabajo de personas contratadas, dependiente 0 independientemente, con la finalidad de realizar una labor creativa o inventiva, susceptible de ser protegida por alguno de los instrumento que señala la Ley, pertenecerán a su empleador o a quien encargó el servicio". Por otro lado, es necesario mencionar que el artículo $2^{\circ}$ de la Ley en cuestión, establece que cualquier persona podrá gozar de los derechos de propiedad industrial pero previamente deberá obtener el título de protección correspondiente.
} 
pleador", sino también "a quien encargó el servicio". Así, a diferencia de lo que ocurre en el caso español, existe total certeza que este tipo de invención no se circunscribe exclusivamente al ámbito de una relación laboral, admitiéndose que pueda emanar de un contrato de prestación de servicios.

En vista de lo anterior, el ámbito subjetivo de esta ley, estará conformado por empleadores y trabajadores, como también por las partes de una relación de servicios civiles.

\section{3) Invenciones objeto de esta regulación}

El ámbito objetivo de esta regulación dice relación con una invención o creación susceptible de ser protegida por alguno de los instrumentos contemplados en la ley ${ }^{79}$. Dichos instrumentos corresponden a las patentes de invención, los modelos de utilidad y los diseños industriales ${ }^{80}$.

Es necesario precisar que la finalidad de estas disposiciones es reglamentar los logros (invenciones) de un trabajador o un prestador de servicios, determinando principalmente a quién corresponde su titularidad, si se generan retribuciones especiales, y cuál sería la jurisdicción competente. En cambio, bien como señala el artículo 18 de la Ley $\mathrm{N}^{\circ} 19.039$, el objeto ${ }^{81}$ del contrato (de trabajo o prestación de servicios) no es la invención, sino el desarrollo de una actividad inventiva o creativa. Lo que es razonable, ya que como apuntábamos, la investigación está dirigida hacia lo desconocido y no pueden garantizarse consecuencias concretas ${ }^{82}$.

\section{4) Remuneración del inventor}

En relación a la remuneración por esta clase de invenciones, el artículo 111 del Reglamento, establece que "El trabajador o quien prestó el

79 Cfr. Arrículo 111 del Reglamento.

so Sobre el particular, surge la duda si pueden ser comprendidos como instrumentos que protegen invenciones, aquellos que no se encuentren contenidos en la Ley $\mathrm{N}^{\circ} 19.039$, pero sí en otras leyes. En principio, los términos del artículo 68 de la Ley son amplios siendo posible aceptar la posibilidad de otros instrumentos. Sin embargo, el tenor del citado artículo 111 resulta bastante restringido, ya que se refiere a una: "labor creativa o inventiva, susceptible de ser protegida por alguno de los instrumentos que señala La Ley". Dado que se trata de un Reglamento que precisamente tiene por objeto desarrollar determinados puntos de una Ley, al referirse a ella sin especificaciones, naturalmente debe entenderse que se trata solo de aquella por la cual precisamente fue dictado. Por tanto, la regulación de estas invenciones solo abarcaría instrumentos de protección contenidos en la Ley citada.

81 Erróneamente la norma utiliza la expresión "naturaleza", ya que de acuerdo a su sentido lógico hubiera correspondido emplear el término "objeto", por estar refiriéndose a la prestación y no al carácter del contrato.

82 Gómez SeGAde, José Antonio: (n. 20), pp. 121-122. 
servicio, solo tendrá derecho a la remuneración o retribución señalada en el respectivo contrato de trabajo o de prestación de servicios". Ahora bien, esta disposición debe ser complementada por el párrafo tercero del artículo 69 de la Ley $\mathrm{N}^{\circ} 19.039$, de cuyo tenor se desprende que corresponderá una retribución adicional a la persona que logre una invención que exceda el marco de la que fue encargada ${ }^{83}$. Nos parece sumamente ambigua esta norma, ya que no se detalla en lo más mínimo a qué se refiere este "exceso del encargo". Sobre este punto, tal como indicábamos cuando tratamos el régimen español, la determinación de este exceso resultará un ejercicio sumamente complejo, que seguramente será fuente de conflictos entre las partes.

Luego, el párrafo $2^{\circ}$ del artículo 112 del Reglamento establece que tal retribución adicional se determinará en función de la importancia comercial e industrial de la creación, la que será fijada de común acuerdo por las partes o por el tribunal especial (que más adelante veremos), en caso que el acuerdo no se produzca. Entendemos que razonablemente tal importancia debiera versar sobre la valoración económica de la invención, por ser el punto de mayor interés para una empresa, cualquiera sea la forma en que se manifieste (abaratamiento de costos, procedimientos, etc.).

No podemos dejar de manifestar que es criticable la técnica legislativa utilizada en este punto, en el sentido de establecer la regla general (solo se tendrá derecho a la remuneración establecida en el contrato) en el Reglamento, y la excepción (retribución adicional) en la Ley.

Por último, con respecto a la naturaleza de la retribución adicional en nuestra opinión esta tiene un carácter salarial, obviamente en el supuesto de una relación laboral. Lo anterior, debido que la remuneración es definida como las contraprestaciones en dinero que debe percibir el trabajador por causa del contrato de trabajo (artículo 41 del Código del Trabajo), pudiendo apreciarse que es bastante amplia la esfera de aplicación de dicho concepto, ya que prácticamente cualquier clase de desembolso que se efectúe al trabajador durante la vigencia de la relación laboral, deberá recibir tratamiento salarial, salvo que se halle ex-

83 Artículo 69 DS $\mathrm{N}^{\circ} 177$ (párrafos $2^{\circ}$ y $3^{\circ}$ ) "Sin embargo, si para llevar a cabo la invención se hubiere beneficiado de modo evidente de los conocimientos adquiridos dentro de la empresa y urilizare medios proporcionados por esta, tales facultades y derechos pertenecerán al empleador, en cuyo caso este deberá conceder al trabajador una retribución adicional por convenir por las partes. Lo anterior será extensivo a la persona que obcuviere una invención que exceda el marco de la que le hubiere sido encargada". Al referirse a un encargo, parece lógico entender que este emana de un acuerdo contractual (expreso o tácito), que puede manifestarse ya sea en un contrato de trabajo, o bien de prestación de servicios. Por tanto, esta norma se encuentra dirigida a las invenciones de servicios. 
presamente exceptuado de tal calificación ${ }^{84}$, situación en la que no encuentra la retribución adicional en cuestión.

\section{5) Estipulación en contrario}

El régimen antes expuesto puede ser alterado por un pacto expreso entre las partes que conste en el respectivo contrato de trabajo o de prestación de servicio ${ }^{85}$. En este sentido, sería perfectamente posible estipular que la titularidad jurídica de esta clase de invención pertenecerá en un cierto porcentaje al trabajador ${ }^{86}$.

\section{B. Invenciones Mixtas}

Esta clase de invenciones se contemplan en el párrafo $2^{\circ}$ del artículo 69 de la Ley en análisis, en el cual se prescribe que "si para llevar a cabo la invención se bubiere beneficiado de modo evidente de los conocimientos adquiridos dentro de la empresa y utilizare medios proporcionados por esta, tales facultades y derechos pertenecerán al empleador, en cuyo caso este deberá conceder al trabajador una retribución adicional por convenir por las partes".

Tal como en LP española, en este supuesto se debe partir de la premisa de que no concurran las circunstancias previstas para la invención de servicios ${ }^{87}$. Así, el inventor no tiene que haber sido contratado para trabajar en la investigación respectiva. Eso sí, la invención tendrá que estar relacionada con la actividad profesional que se desarrolla en la empresa, de lo contrario se trataría de una invención libre, según se expone más adelante.

Luego, en el logro de la invención deben converger conjuntamente dos factores: que predominen los conocimientos que se hayan adquirido dentro de la empresa; y se utilicen los medios proporcionados por esta ${ }^{88}$.

El párrafo $2^{\circ}$ del artículo 41 del Código del Trabajo, dispone que no constiruyen remuneración "las asignaciones de movilización, de pérdida de caja, de desgaste de herramientas y de colación, los viáticos, las prestaciones familiares otorgadas en conformidad a la ley, la indemnización por años de servicios establecidas en el artículo 163 y las demás que proceda para al extinguirse la relación contractual ni, en general, las devoluciones de gastos en que se incurra por causa del trabajo".

85 Cfr. Artículo 68 Ley $\mathrm{N}^{\circ} 19.039$ y Artículo 111 del Reglamento. Es necesario indicar que el artículo 111 utiliza la expresión contrato de trabajo, debiendo entenderse que se comprenden en ella no solo los contratos individuales, sino también los contratos y convenios colectivos, por tener estos últimos mayor jerarquía jurídica que el primero. invenciones creadas en sus instalaciones, sería difícil imaginar que se acuerde otorgar la totalidad de su ritularidad al trabajador.

Los conceptos "conocimientos" y "medio" son tratados en la p. 17. Por su parte, la exigencia de simultaneidad se desprende de la conjunción copulativa " $y$ ", que se uriliza para unir palabras o cláusulas en concepto afirmativo (Diccionario de la Lengua Española, vigésima 
En este orden, llama poderosamente la atención que el Reglamento solo exige que concurra alternativamente solo uno de ellos, esto es, ya sea los conocimientos, o bien los medios ${ }^{89}$. Es decir, existe una clara contradicción entre lo dispuesto en la Ley y en su Reglamento, no pudiendo afirmarse que se trata de un desarrollo o clarificación, por parte de este último, de un punto de la ley. Finalmente, basta mencionar que siguiendo la jerarquía del ordenamiento jurídico deberá preponderar el criterio legal.

\section{1) Titularidad}

La titularidad de estas invenciones pertenecerán a la empresa, según lo dispuesto en el citado artículo $69^{90}$. Es interesante constatar que esta atribución se efectúa en similares términos que las invenciones de servicios, de manera que el empleador adquiere directamente los derechos sobre el invento, sin que se requiera un acto dispositivo del trabajador.

En este punto, existe una evidente diferencia con la regulación española, que en esta categoría no otorga directamente la titularidad al empresario, sino que le concede un derecho de opción para adquirirla, lo cual implica que si la ejerce será efectivamente el titular de la invención, pero a título derivado.

\section{2) Contrato de trabajo o prestación de servicios}

Del tenor de la disposición antes mencionada, en principio puede pensarse que esta clase de invenciones solo está dirigida a personas vinculadas por una relación de índole laboral, ya que se utilizan únicamente expresiones propias de dicho género (contrato de trabajo, empleador, trabajador). Sin embargo, el artículo 112 del Reglamento, al atender a la retribución que se genera por esta invención, se refiere tanto al trabajador como al prestador de servicios. Por tanto, es posible inferir que este régimen también tiene aplicación para las partes de un contrato de prestación de servicios. Lo que resulta bastante apropiado, ya que no existen fundamentos razonables que justifiquen esta exclusión.

segunda edición, 2001, p, 1086). Asimismo, recordemos que la normativa española contempla los mismos factores; sin embargo, se insta alternativamente su presencia.

En efecto, el artículo 112 del Reglamento, establece: "Los derechos de propiedad industrial de quienes hayan sido contratados para realizar un función distinta a la creativa o inventiva, pertenecerán a su creador o inventor, a menos que para llevar a cabo dicha actividad haya utilizado en forma evidente conocimientos adquiridos durante su permanencia en la empresa empleadora o utilizará los medios proporcionados por esta (...)". Se utiliza la conjunción disyuntiva "o", que denora diferencia, separación o alternativa entre dos o más personas, cosas o ideas (Diccionario de la Lengua Española, vigésima segunda edición, 2001, p. 1086).

90 Del mismo modo, artículo 112 del Reglamento. 


\section{3) Invenciones objeto de esta regulación}

Sobre este tema nos remitimos a lo expuesto bajo el mismo título, en el apartado de las invenciones de servicios.

\section{4) Retribución del inventor}

Con respecto a la retribución por estas clase de invenciones, se establece que el empleador "deberá conceder al trabajador una retribución adicional por convenir por las partes" (artículo 69 Ley $\mathrm{N}^{\circ} 19.039$ ).

Esta retribución se fijará en función de la importancia comercial e industrial de la invención, la que será fijada de común acuerdo por las partes o por el tribunal especial (que veremos más adelante), en caso que el acuerdo no se produzca (artículo 112 Reglamento). Prácticamente es el mismo régimen que las invenciones de servicios, salvo que en este supuesto no se aplica la norma relativa al exceso del encargo (párrafo $3^{\circ}$, artículo 69 Ley $\mathrm{N}^{\circ} 19.039$ ).

En relación a la naturaleza de esta retribución en nuestra opinión parece ser (como en el caso español) que la compensación en cuestión no tiene naturaleza salarial, ya que este pago no va dirigido a retribuir la prestación de los servicios contratados, sino más bien se trata de un precio que el empresario está abonando por corresponderle la titularidad de la invención, que directamente le pertenece por disposición legal.

Sin perjuicio de lo anterior, no sería descartable la posición contraria, ya que según veíamos, la amplia conceptualización legal de remuneración como toda contraprestación que se reciba a consecuencia del contrato, perfectamente podría dar pie a que esta retribución adicional, independiente que la actividad inventiva no sea objeto del contrato, tenga naturaleza salarial, dado que la invención fue producto predominantemente de los medios y conocimientos adquiridos en la empresa. Es decir, precisamente en gran parte a consecuencia de la relación laboral, según se dispone en el artículo 41 del Código del Trabajo.

\section{Invenciones Libres}

Repasemos que esta clase de invenciones son aquellas pertenecientes al trabajador, no reconociéndose a la empresa ningún derecho. A diferencia del caso español ${ }^{91}$ se encuentran expresamente delimitadas en el párrafo $1^{\circ}$ del artículo 69 de la Ley, a cuyo tenor "La facultad de solicitar el privilegio, así como los eventuales derechos de propiedad industrial derivados de

\footnotetext{
91 No se encuentran definidas en la LP, derivándose su delimitación de un análisis conjunto de los artículos 15, 16 y 17 LP, de esta forma es posible obtener un concepto negativo de este tipo de invenciones.
} 
las invenciones realizadas por el trabajador que, según contrato de trabajo, no se encuentra obligado a realizar una función inventiva o creativa, le pertenecerán en forma exclusiva". Es posible constatar que en principio estas invenciones se circunscriben a un ámbito laboral. Sin embargo, el artículo 112 del Reglamento, amplía esta esfera, ya que se refiere a quienes hayan sido contratados para realizar una función distinta a la creativa o inventiva, sin singularizar la naturaleza de esta contratación. A mayor abundamiento, el citado artículo al atender la retribución adicional de las invenciones mixtas contemplaba no solo al trabajador, sino también al prestador de servicios.

En suma, estas invenciones deben efectuarse durante la vigencia de un contrato laboral o de servicios, siendo la actividad inventiva ajena a dichas convenciones. Además, el inventor para alcanzar su logro, no podrá beneficiarse de modo evidente de los conocimientos adquiridos dentro de la empresa, ni utilizar medios proporcionados por esta, de lo contrario tendrá la categoría de mixta.

\section{Renuncia de derechos}

El artículo 71 de la Ley contempla la irrenunciabilidad de los derechos del trabajador contenidos en las normas analizadas, señalándose que "Los derechos establecidos en beneficio del trabajador en los artículos precedentes, serán irrenunciables antes del otorgamiento de la patente o del modelo de utilidad, según corresponda. Toda cláusula en contrario se tendrá por no escrita". Esta norma debe complementarse con el artículo 114 del Reglamento, el cual prescribe que "La irrenunciabilidad de los derechos a los que se refiere el artículo 71 de la Ley, procederá solo en aquellos casos en que la función primordial del trabajador, según su contrato de trabajo, no sea la de realizar una actividad inventiva o creativa".

De un examen conjunto de dichas disposiciones, se pueden colegir los siguientes aspectos:

1) A primera vista, esta imposibilidad de renuncia estaría relacionada únicamente con patentes de invención y modelos de utilidad, ya que solo ellos son nombrados explícitamente (artículo 71). Por lo que parece ser que, en este punto, se estaría prescindiendo del diseño industrial. Sin embargo, teniendo en cuenta que, como veíamos, este último es uno de los instrumentos de protección de invenciones contemplados en la ley (que debe ser considerado en el orden de las categorías de servicios y mixtas), como a su vez que no se excluye abiertamente en el artículo señalado, resulta razonable entender que, pese a lo poco feliz del tenor legal, esta irrenunciabilidad también debiera comprenderse para el mencionado diseño. 
2) De acuerdo a lo establecido en la norma reglamentaria, se desprende que la imposibilidad de renuncia solo tendría aplicación en caso de invenciones mixtas o libres. Lo anterior, a consecuencia que se establece tal prohibición cuando la investigación no sea la labor fundamental del trabajador, siendo este requerimiento encuadrable exclusivamente en las invenciones citadas. Así, se descartan las invenciones de servicios, ya que en estas el objeto del contrato respectivo precisamente es el desarrollo de una actividad inventiva ${ }^{92}$. En este sentido, en el supuesto de invenciones libres esta irrenunciabilidad se encontrará mayormente referida a la titularidad de la invención que pertenece al trabajador. Conviene destacar que dicha deducción no es aplicable a las invenciones mixtas, dado que su titularidad se otorga directamente a la empresa. Más bien, en esta categoría la prohibición de renuncia debiera versar preferentemente sobre el derecho a la retribución adicional.

3) La irrenunciabilidad se contempla solo para trabajadores, no mencionándose el prestador de los servicios. Por un lado, podría sostenerse que no debiera interpretarse de manera tan estricta la norma, dando cabida al caso indicado, básicamente por tener ambos (trabajador prestador de servicios), en este orden, el mismo régimen. Sin embargo, también podría considerándose que dicha irrenunciabilidad es una proyección de aquella de índole general, establecida en el artículo $5^{\circ}$ del Código del Trabajo, por lo que solo tendría aplicación para el trabajador dependiente; con esta última posición estaríamos más de acuerdo.

4) Lo que se prohíbe al trabajador es la renuncia de derechos con anticipación al otorgamiento de la patente o modelo. Al ponerse como límite la citada concesión, es lógico deducir que a la prerrogativa que se le da mayor trascendencia es la titularidad invención, pero como analizábamos esta solo pertenece originalmente al inventor en el supuesto de las denominadas libres.

\section{E. Información y secreto}

El empleador o quien encargó el servicio tendrá el derecho a que la invención o trabajo encargado permanezca en secreto (párrafo $2^{\circ}$ del artículo 111 del Reglamento). Este derecho resulta imprescindible, ya que si se ventila la invención a terceros, se perdería la novedad, requisito básico para obtener la patente.

A su vez, los trabajadores o prestadores de servicios son obligados a comunicar a su empleador o a quien encargó el servicio, de la actividad

92 Es posible distinguir la diferencia con la normativa española que contempla la irrenunciabilidad de derechos para todas las clases de invenciones. 
creativa o inventiva que hubieren realizado al amparo del respectivo contrato de trabajo o prestación de servicios, según el caso (artículo 113 del Reglamento). No se especifica la forma como debe efectuarse dicha comunicación, por lo que en principio podría entenderse la posibilidad verbal, como escrita.

Por su parte, distintamente del supuesto español, no se establece sanción si se incumple dicha obligación.

\section{F. Funcionarios de universidades o instituciones de investigación}

Con respecto a esta clase de personal se establece que la facultad de solicitar el respectivo privilegio así como los eventuales derechos de propiedad industrial derivados de la actividad inventiva de la persona contratadas en una relación dependiente o independiente, por universidades o las instituciones de investigaciones incluidas en el DL $\mathrm{N}^{\circ} 1.263$ de 1975, sobre administración financiera del Estado ${ }^{93}$, pertenecerán a estas últimas, o quienes estas determinen, sin perjuicio de que los estatutos de dichas entidades regulen las modalidades en que el inventor o creador participe de los beneficios obtenidos por su trabajo.

\section{G. Orden jurisdiccional}

Las controversias que se susciten en el ámbito de las invenciones laborales serán competencia del Tribunal Arbitral de Propiedad Industrial (artículo 71 de la Ley $N^{\circ}$ 19.039). Este Tribunal estará integrado por tres miembros que serán designados, cada dos años, por el Ministerio de Economía, Fomento y Reconstrucción, uno de los cuales será de su libre elección, otro será elegido de una terna que presentará la Corte de Apelaciones de Santiago.

\section{CONCLUSIONES}

Del examen de esta regulación puede constatarse que sus objetivos principales están encaminados a resguardar los legítimos intereses de las empresas e instituciones, de variados sectores, cuya misión es llevar a efecto tareas de investigación. Lo anterior, a través del reconocimiento de la titularidad de aquellas sobre las obtenciones que en este ámbito alcancen sus trabajadores o personas externas contratadas para ello, que según

93 El mencionado DL contempla los servicios e instituciones del sistema de administración financiera del Estado, algunos de los cuales desarrollan labores de investigación, tales como: el Instituto de Investigaciones Tecnológica, Instituto de Investigaciones Geológicas, e Instituto de Investigaciones Agropecuarias. 
veíamos, se encuentran amparadas en el régimen de las denominadas invenciones de servicio y mixtas.

Este criterio nos parece absolutamente razonable, ya que el desarrollo actual de la técnica, prácticamente en todos los niveles, involucra inversiones de relevancia, que solo pueden ser asumidas por entidades de cierta categoría financiera y estructural. Teniendo en cuenta este escenario, si existiera incertidumbre acerca del derecho de estas sobre las invenciones conseguidas en el marco de sus diferentes proyectos, se pondría en serios problemas este tipo de industria, siendo a la larga la sociedad en su totalidad la gran afectada.

Por tal motivo, resulta necesaria en estos tiempos esta clase de regulación. En este orden, la opción de normar esta materia en leyes de Propiedad Industrial, como a su vez, el entregar el conocimiento de eventuales controversias a un tribunal ordinario o arbitral, nos parece la solución más acorde para enfrentar la complejidad del tema. En efecto, si se hubiera otorgado competencia a la jurisdicción laboral, dado su carácter sobreprotector del trabajador, se correría el riesgo que se desvirtuarse la correcta aplicación de la normativa en cuestión.

Sin perjuicio de lo anterior, no debemos olvidar que existen un conjunto de puntos que requieren mayor certeza. Entre los cuales, se destaca principalmente, en el caso español, si esta regulación es aplicable o no a los contratos de prestación de servicios. A su vez, en ambas legislaciones, el tema referido a la determinación de la retribuciones adicionales, que exige de parámetros más exactos, bajo el interés de prevenir conflictos, dada la ambigüedad de la preceptiva. Y, específicamente en el ámbito chileno, se requiere una mayor correspondencia entre las disposiciones legales y reglamentarias, que incluso contemplan aspectos en contradicción.

Por último, debemos manifestar que el conocimiento de este tipo de causas a nivel jurisdiccional no es común, lo que puede dar cuenta que los partícipes de los proyectos de investigación tienen claridad acerca de los derechos y roles que le corresponden a cada uno. Luego, esta constatación no es excusa para no perfeccionar y actualizar esta legislación, ya que en consideración a la dinámica de su objeto de regulación, se corre el riesgo de que en cualquier momento ella quede desfasada con la nueva realidad.

\section{ABREVIATURAS}

DL : Decreto Ley, Chile

ET : Estatuto de los Trabajadores; España

LCT : Ley de Contrato de Trabajo de 27 enero 1944, España

LDI : Ley 20/2003, de 7 julio, sobre el Diseño Industrial, España

LP : Ley 11/1986, de 20 marzo, de Patentes, España 


\section{BIBLIOGRAFÍA}

- Alonso Olea, Manuel y Casas BaAmonde, María Emilia: Derecho del Trabajo (Civitas, Madrid, 1997).

- Albiol Montesinos, Ignacio: "Los inventos del trabajador, el socio industrial y la ejecución de obra", en Revista de Derecho Privado, 1975, pp. 109-126.

- Blanco Jiménez, Araceli: Protección Jurídica de las Invenciones Universitarias y Laborales (Aranzadi, Navarra, 1999).

- Bercovitz, Alberto: "Anotaciones a la regulación legal española sobre invenciones laborales", en Actas de Derecho Industrial, 1976, pp. 49-91.

- Diéguez Cuervo, Gonzalo: Lecciones de Derecho del Trabajo (Marcial Pons, Madrid, 1995).

- ESTUPIÑán CÁCERES, Rosalía: Las invenciones laborales en la empresa (Editoriales de Derecho Reunidas, Madrid, 2003).

- Feas Costillas, Javier: "Las invenciones laborales en la Ley de Patentes de 1986", en Revista del Trabajo, $\mathrm{N}^{\circ}$ 87, 1987, pp. 121-136.

- Gómez Segade, José Antonio: "Derecho a la patente", en FernánDEZ NOvoA, C. y GÓmez SEgAde, J.A.: La modernización del Derecho Español de Patentes (Montecorvo, Madrid, 1984), pp. 103-135.

- Gómez Segade, José Antonio: "Patentabilidad", en Fernández NovoA, C. y GÓmez Segade, J.A.: La modernización del Derecho Español de Patentes (Montecorvo, Madrid, 1984), pp. 45-97.

- Lema Devesa, Carlos: "Las invenciones laborales en la Ley de Patentes de 20 de marzo de 1986", en Derecho y Tecnología, curso sobre innovación y transferencia (dir. y coord. por J. Bisbal/C. Viladás), (Ariel, Barcelona, 1990), pp. 145-156.

- LoIS BASTIDAS, Fátima: La protección del inventor asalariado (Civitas, Madrid, 2000).

- Rodríguez PiÑERo, Miguel: "El nuevo régimen jurídico de las invenciones laborales", en Relaciones Laborales, $\mathrm{N}^{\circ}$ 6, 1986, pp. 41-48.

- Sala Franco, Tomas y Otros: Derecho del Trabajo (Tirant Lo Blanch, Valencia, 1995).

- Sala Franco, Tomás y Vicent Chuliá, Francisco: "El nuevo régimen jurídico de las invenciones laborales", en Actualidad Laboral $\mathrm{N}^{\circ} 4,1988$, pp. 1977-1999. 